\title{
Integrated life-of-mine waste characterisation, scheduling, and quality control for progressive closure at Martabe multi-pit gold mine
}

\author{
SK Grohs PT Agincourt Resources, Indonesia
}

S Pearce Mine Environment Management Ltd, UK

\begin{abstract}
This paper discusses practices developed by PT Agincourt Resources at the Martabe Gold Mine for integration of practical short and medium-term mining practice and long-term strategic planning, for characterisation and optimum placement of mine waste, in a structural tailings and mine waste storage facility. This also includes alignment with the progressive closure strategy adopted at the site for mitigation of acid and metalliferous drainage $(A M D)$ risk.

The mine comprises a complex six-pit operation with three pits currently delivering waste material to an integrated tailings and mine waste storage facility, which has been designed to be constructed as a progressively rehabilitated landform. The waste rock varies significantly both in geochemical and physical properties between the pits, and within each pit, presenting challenges for mine planning and execution of an optimal progressive mine closure strategy. As such, a number of detailed long and medium-term practical mine planning practices have been developed within key areas of mining operations.
\end{abstract}

Keywords: integrated, waste control, progressive rehabilitation

\section{Project overview, location and site characteristics}

Martabe gold and silver mine is situated in northern Sumatra (Figure 1) and comprises six reserve deposits in steep terrain that require a life-of-mine (LOM) plan to be developed with mining activities progressing in the optimal sequence for the best possible Net Present Value (NPV) return on the project, while managing tailings, mine waste disposal and acid and metalliferous drainage (AMD) risk, aligned to the progressive mine closure plan. Due to the limited available storage area for waste, waste materials from the excavations are treated as a byproduct to be scheduled and used for construction of the embankment of the integrated waste storage facility (IWSF) to specific engineering standards. The ore delivery, tailings and mine waste disposal plans therefore need to be aligned to ensure the tailings can be contained relative to the production rate over the LOM.

The IWSF embankment construction process includes utilisation of potentially acid forming (PAF) waste by employing a strategy of progressive sealing (oxygen exclusion) and rehabilitation (vegetation establishment) to manage potential AMD risks and facilitate meeting the closure requirements of the future. The progressive rehabilitation strategy developed for the site is described in detail in previous publications (Pearce et al. 2016, 2017).

Short-term planning practices include execution of a detailed program of waste grade control drilling, sampling, modelling and validation within all mine pits simultaneously to produce a detailed waste grade control model that is reconciled monthly with the LOM reserve waste model. Long-term planning requires consideration of waste delivery from existing and future pits to ensure that the progressive closure strategy is sustainable over LOM operations. This requires that both short-term and LOM planning considers pit optimisation in terms of mining of waste as well as ore, which in itself represents a fundamental paradigm 
shift in how mine planning is approached, as waste is effectively considered in a similar manner to ore for the purposes of both mining operations and planning.

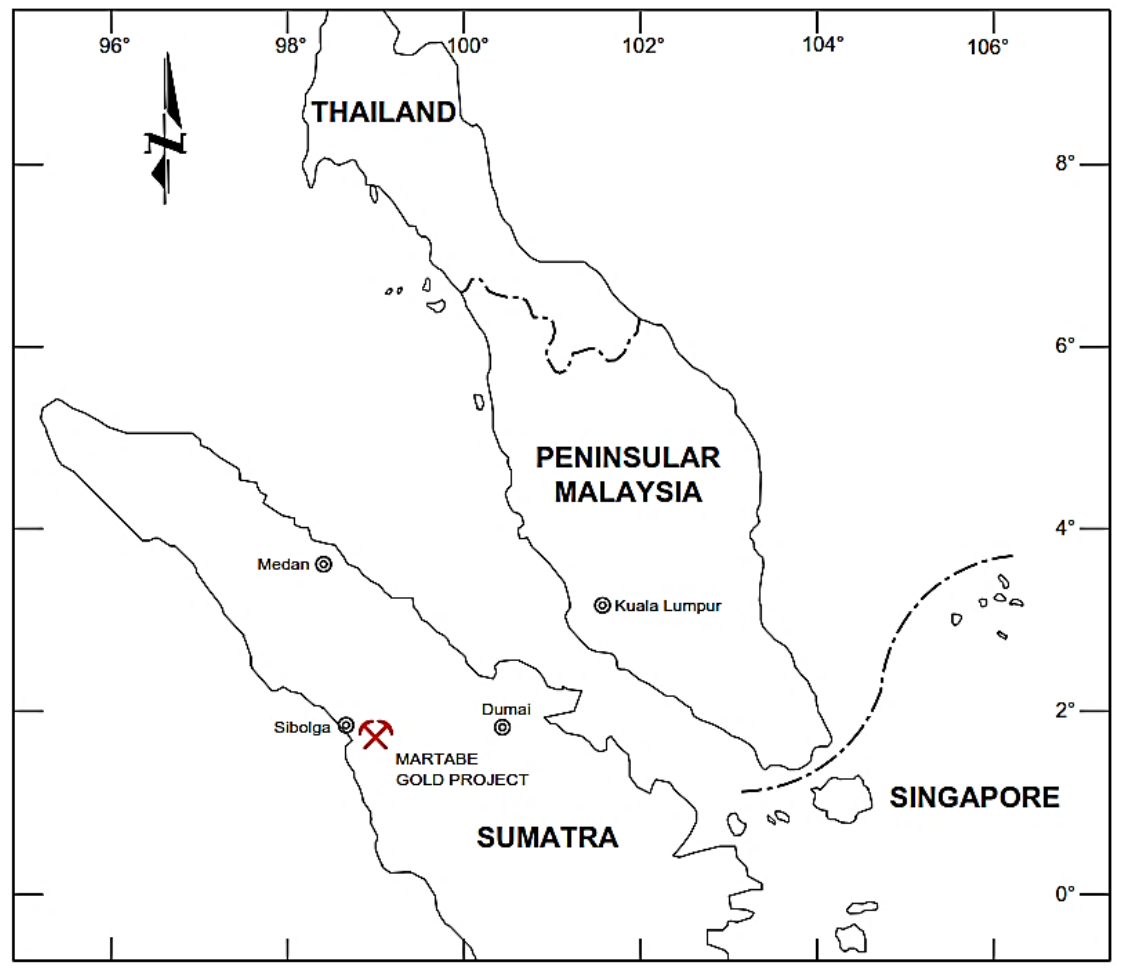

Figure 1 Martabe gold and silver mine location

The mine is situated approximately three kilometres north of the township of Batangtoru (Figure 1) in a seismically active zone between the offshore subduction zone and the Sumatran fault. The mining operation currently includes three open cut pits with a fourth in development stage, an integrated tailings storage facility and dual-purpose valley-fill type waste rock storage facility (Figure 2).

\section{MARTABE OVERVIEW}

\section{World Class Gold District}

$>$ Six known deposits within a $5 \mathrm{~km} \times 6 \mathrm{~km}$ area with Purnama the largest to date, closely followed by Ramba Joring

> Part of a large-scale mineralised district which has the potential to host further gold and gold-copper deposits
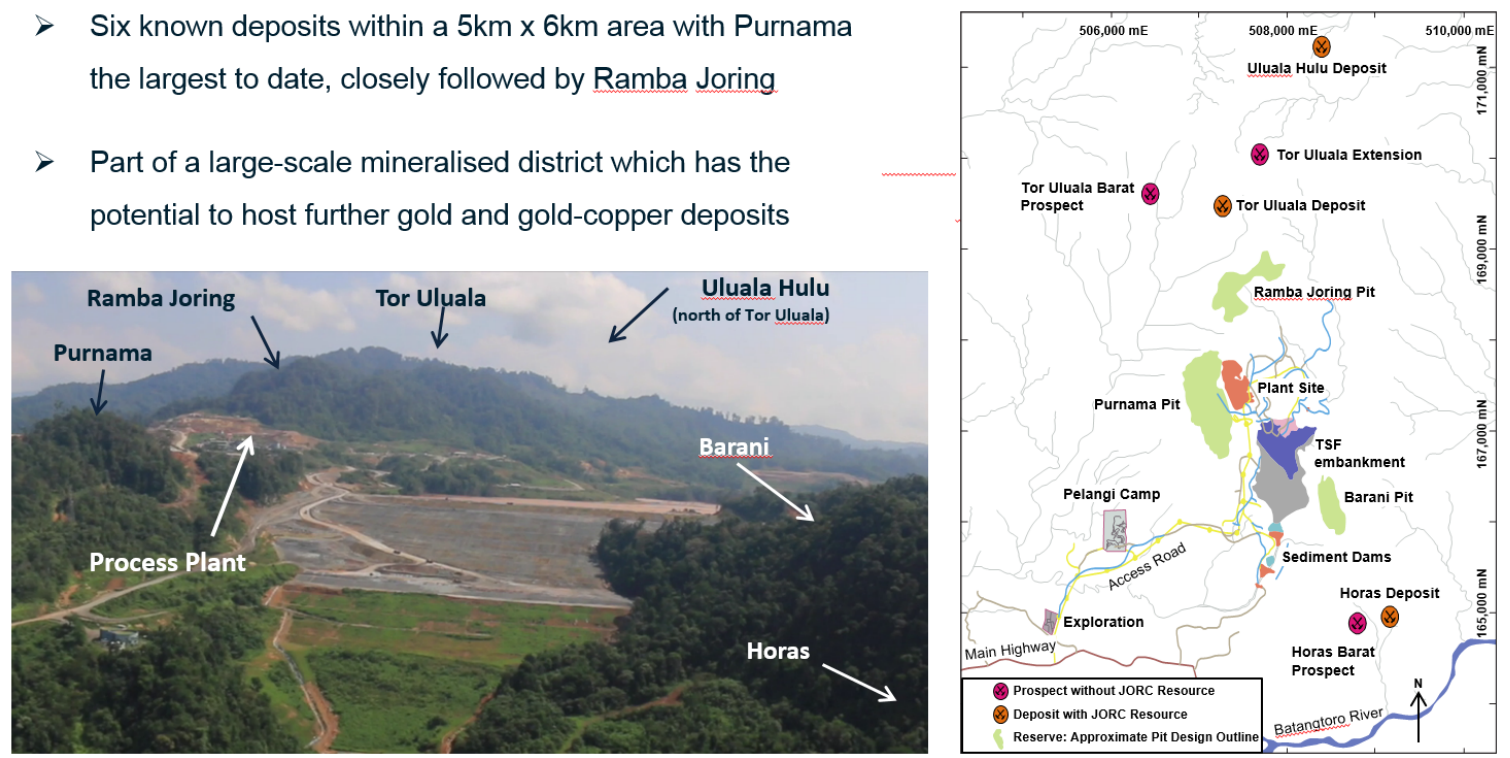

Figure 2 General layout of Martabe operation 


\section{Operational planning overview}

The mine (Figure 2) comprises a complex six-pit operation with three pits currently delivering waste material to an integrated tailings and mine waste storage facility. The waste rock varies significantly both in geochemical and physical properties between the pits, and within each pit, presenting challenges for mine planning and execution of an optimal progressive mine closure strategy (Pearce et al. 2016, 2017). As such a number of detailed long- and medium-term practical mine planning and management practices have been developed at the site to guide operations.

The long-term planning method requires consideration of waste delivery from existing and future pits to ensure that the progressive closure strategy is sustainable over LOM operations. This requires that LOM planning considers pit optimisation in terms of mining for waste delivery as well as ore.

Short-term planning practices include execution of a detailed program of waste grade control drilling, sampling, modelling and validation within all mine pits simultaneously to produce an integrated detailed waste grade control model that is reconciled monthly with the LOM reserve waste model. The validated waste grade control model is then used to inform a rolling three month forward waste delivery and placement plan to guide IWSF construction (build plan). Placement of waste material at the IWSF is then subject to detailed validation testing to confirm placement is in accordance with the material placement specification and sequencing within the embankment. A detailed monitoring program consisting of instrumentation installed within the placed material on the embankment together with sampling of surface and groundwater downstream of the IWSF which provides validation and quality assurance data to assess performance of the overall management process.

The integration between long-term planning, short-term planning and operational control is driven by the establishment of effective management methods and assumption of responsibility by all key site teams. Table 1 shows how key management tasks and responsibilities are defined at the site.

Table $1 \quad$ Long- and short-term management structure

\begin{tabular}{|c|c|c|}
\hline $\begin{array}{l}\text { Management } \\
\text { phase }\end{array}$ & Management task & $\begin{array}{l}\text { Site team with key } \\
\text { responsibility }\end{array}$ \\
\hline \multirow{5}{*}{$\begin{array}{l}\text { Long-term } \\
\text { planning }\end{array}$} & Materials testing and characterisation & Mine geology \\
\hline & Classification and modelling & Mine geology \\
\hline & Pit staging plan and waste schedule & Mine planning \\
\hline & Integrated waste storage facility (IWSF) design and build plan & IWSF \\
\hline & Pit backfill plan & Mine planning \\
\hline \multirow{4}{*}{$\begin{array}{l}\text { Short-term } \\
\text { planning }\end{array}$} & Waste grade control validation and reconciliation & Mine geology \\
\hline & Waste treatment & Mine planning \\
\hline & Waste excavation and movement & Mine planning \\
\hline & Waste placement and validation & IWSF \\
\hline \multirow{2}{*}{$\begin{array}{l}\text { Operational } \\
\text { control }\end{array}$} & Water treatment & Operations \\
\hline & Monitoring and assurance & Mine environment/IWSF \\
\hline
\end{tabular}

The process of reporting, documenting and review of the activities carried out in each management task includes two main review activities:

- Monthly AMD reporting (IWSF, mine geology, mine planning, environment).

- Tri-annual AMD reviews (external review by all key teams contributing). 
The review activities have a number of general objectives that include ensuring that the integrated planning process is documented, to provide regular quality assurance/quality control ( $Q A / Q C$ ) of the process, to provide regular and proactive feedback between operational teams, to provide validation and ultimately to ensure ongoing optimisation of the approach.

\subsection{Long-term planning}

Figure 3 shows a high-level schematic of how the long-term planning process integrates waste scheduling from multiple pits with delivery to waste containment facilities and includes the following activities:

- Characterisation of waste materials in all mine pits within a reserve model that uses a defined AMD waste classification system as part of waste block modelling.

- Production of a pit staging plan that reports the volumes of material mined by waste class over LOM.

- Utilisation of the pit staging plan to produce an integrated LOM waste schedule showing volumes of materials produced by waste class over LOM.

- Utilising the LOM waste schedule to produce a LOM build plan for all waste storage facilities and pit backfill areas.

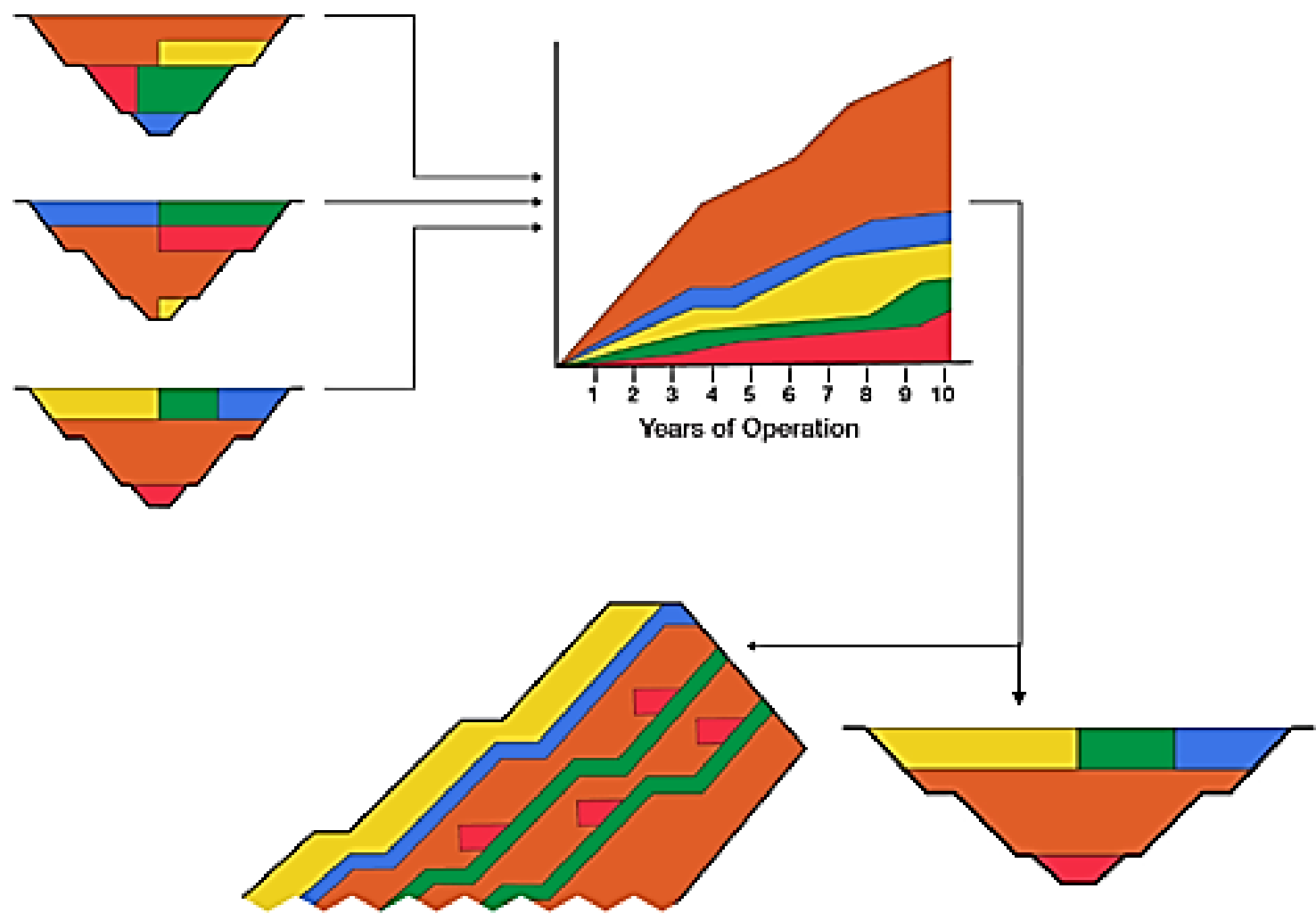

Figure 3 Conceptual figure showing multi-pit life-of-mine scheduling and waste placement planning within waste disposal destinations (integrated waste storage facility embankment and in-pit filling shown)

While Figure 3 shows the concept of long-term planning and scheduling, Figure 4 shows a snapshot from the actual reserve waste block model from one of the pits at the site, different colours represent different waste classes. In addition, Figure 4 also shows the actual integrated multi-pit LOM waste schedule resulting from utilisation of the reserve waste block models into the mine plan, with annual waste production by waste class and volume is shown as chart. 


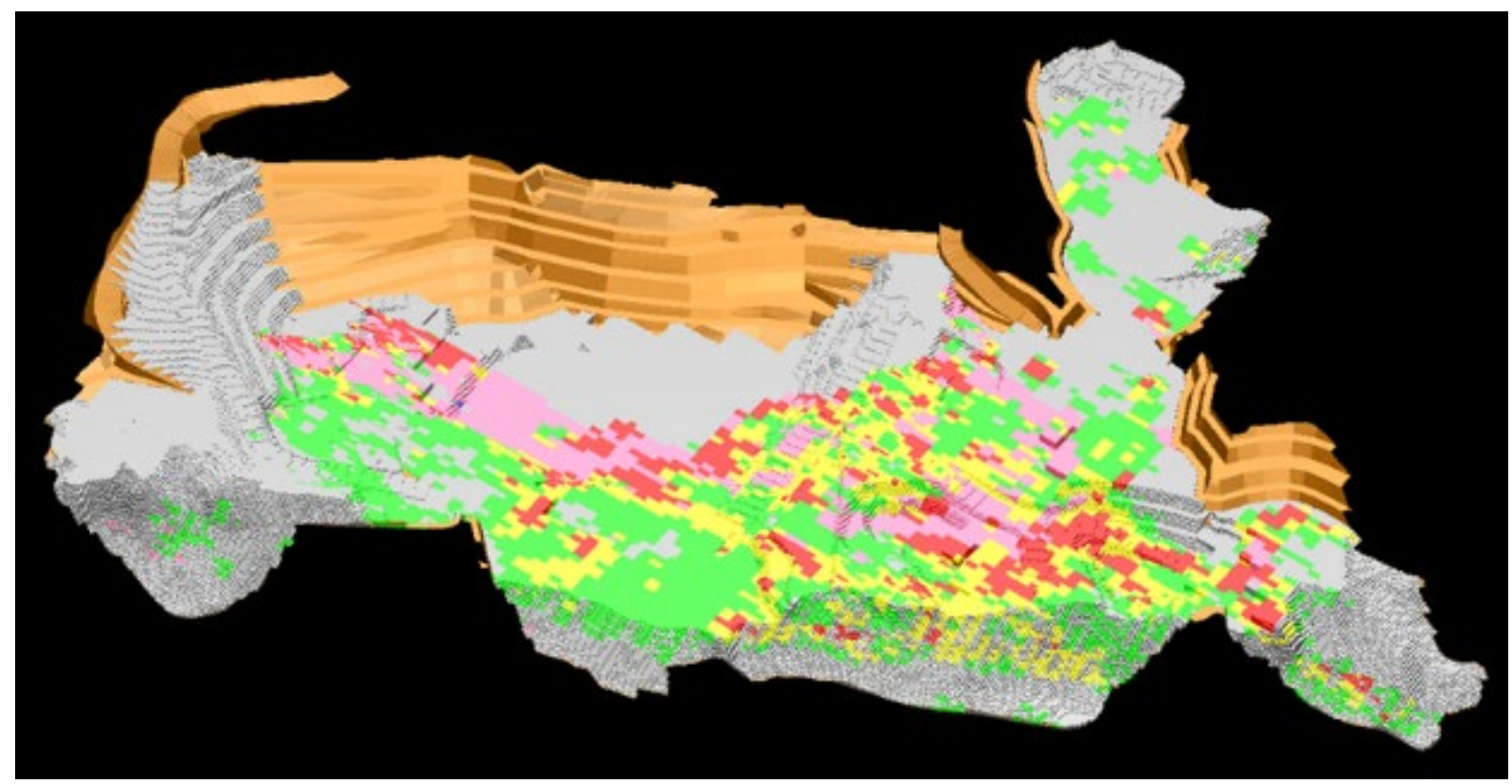

2018-Integrated LOM Waste schedule

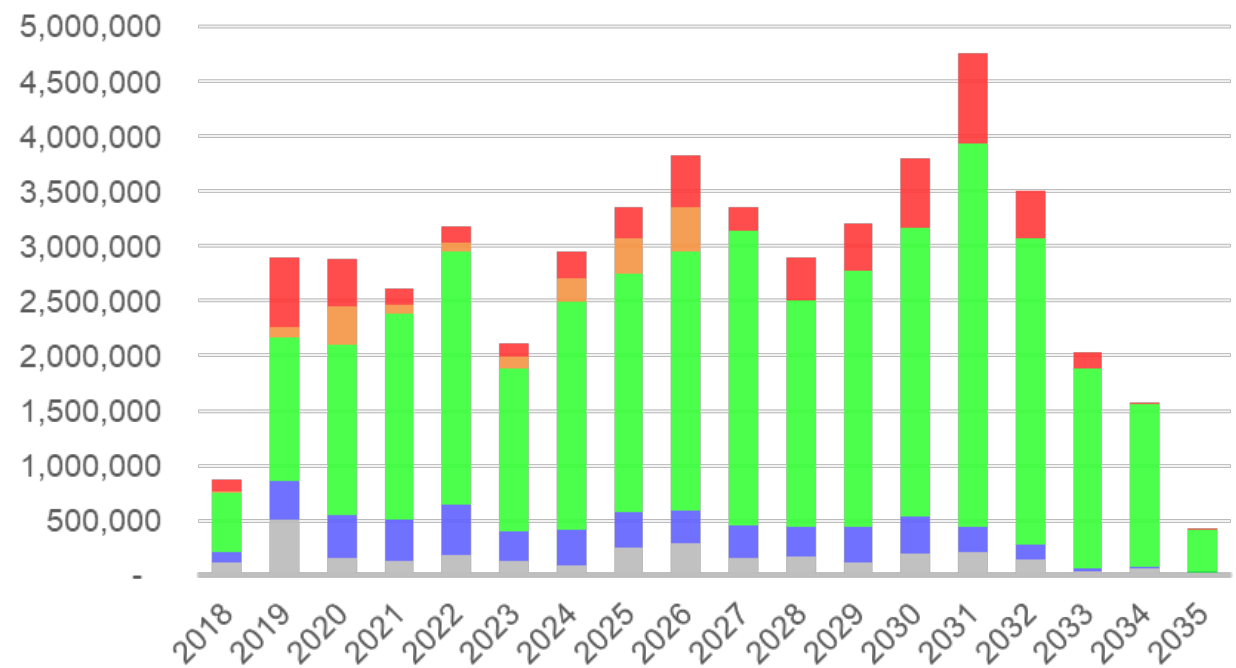

Figure 4 Single pit life-of-mine (LOM) reserve block model snapshot showing waste material type by class (colour) and integrated LOM waste schedule showing annual waste production volumes by waste class (colour)

The LOM schedule developed from the reserve waste block models (Figure 4) is integrated with the progressive rehabilitation and closure plan to determine the projected LOM materials balance with respect to waste material types and potential waste delivery to the IWSF. Figure 5 shows the conceptual progressive rehabilitation concept with key features of the construction with respect to materials requirements identified as:

- Supply of PAF material that requires to be encapsulated.

- Supply of 'sealing layer' material that is used to create an oxygen 'exclusion' barrier to minimise AMD risks.

- Supply of 'growth medium layer' material that is used to create an outer zone of material suitable to support rehabilitation objectives (re-vegetation). 


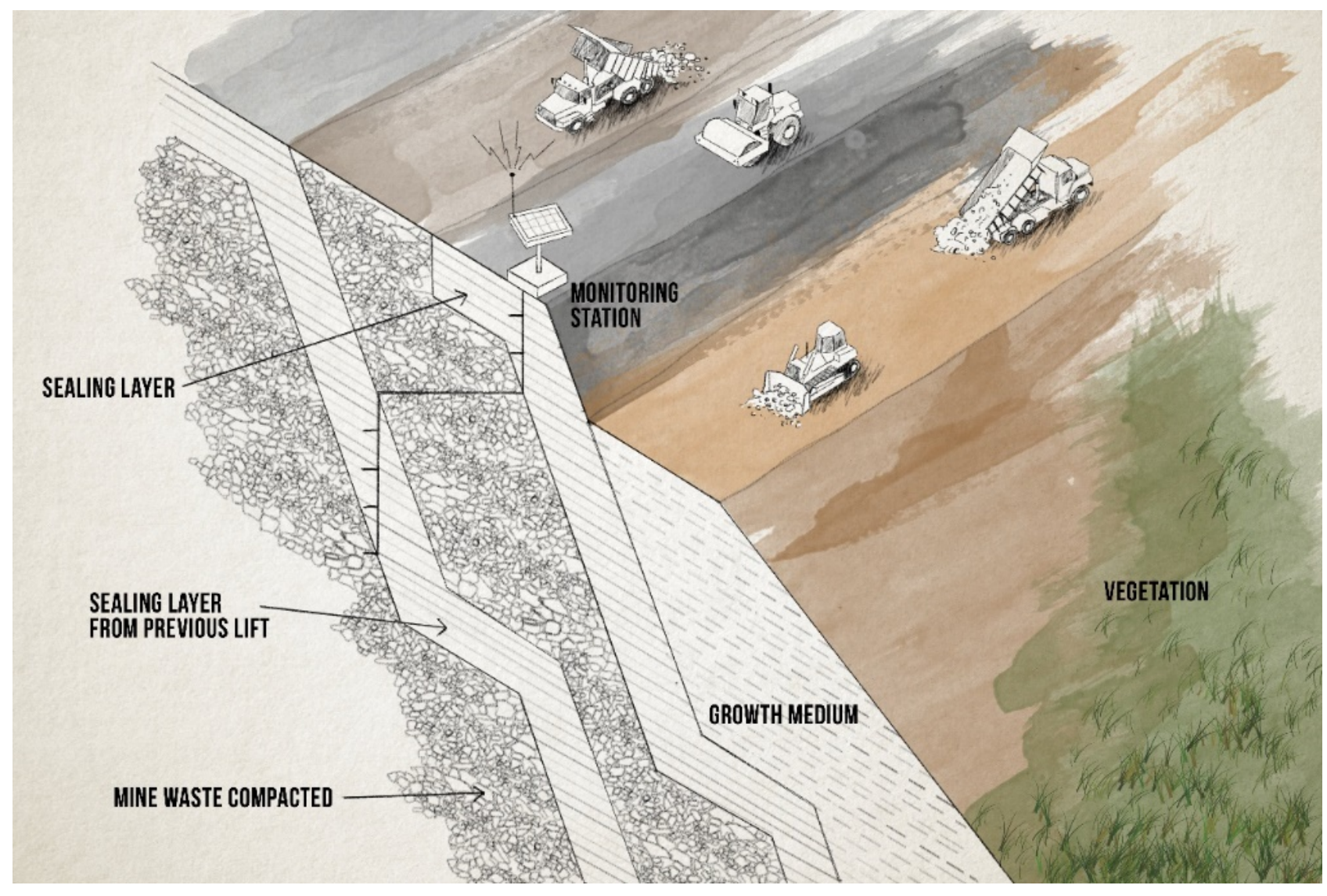

Figure 5 Conceptual section showing progressive rehabilitation strategy for integrated waste storage facility embankment

To construct the IWSF embankment in accordance with the progressive rehabilitation strategy shown in Figure 5 the LOM waste schedule must support the materials requirements of the build plan with respect to volumes and timing of delivery of the different waste types over time.

\subsection{Short-term planning}

Short-term planning includes activities related to waste and AMD management that apply to the day-to-day operations of the mining production process. Figure 6 shows the concept for short-term planning as part of mining activities, and Figure 7 shows the concept for short-term planning as part of waste placement activities.

Short-term planning activities related to waste mining and production activities as shown in Figure 7 include:

- Waste grade control drilling and sampling within each pit (reported monthly).

- Waste modelling and reconciliation with each pit (reported monthly).

- Preparation of daily dig plans.

- Marking out waste mining areas (daily).

- Movement, tracking and placement verification of waste (real time using fleet management system).

- Forward planning for waste placement using rolling three month waste delivery and placement plan. 


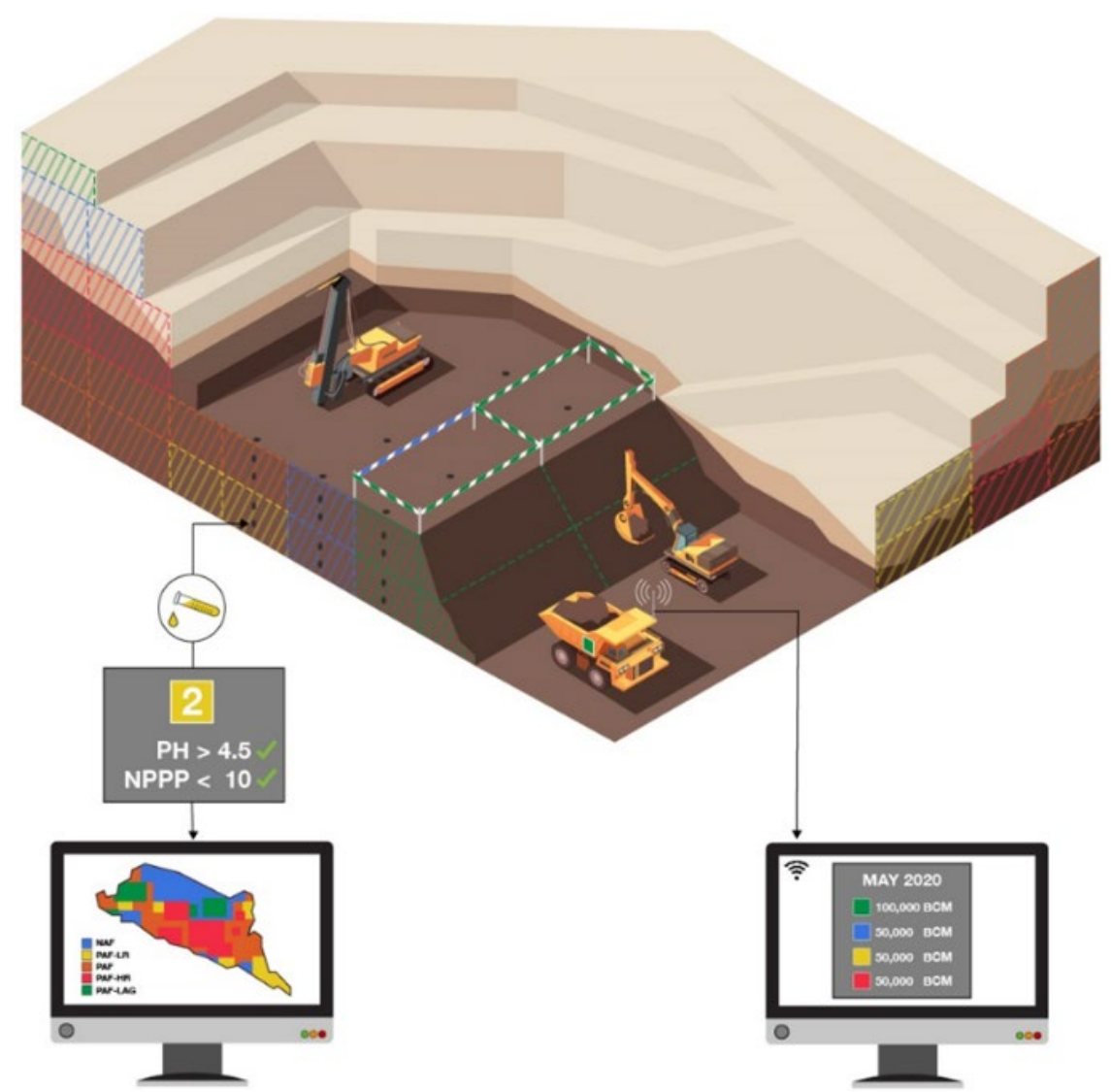

Figure 6 Conceptual figure showing short-term planning process

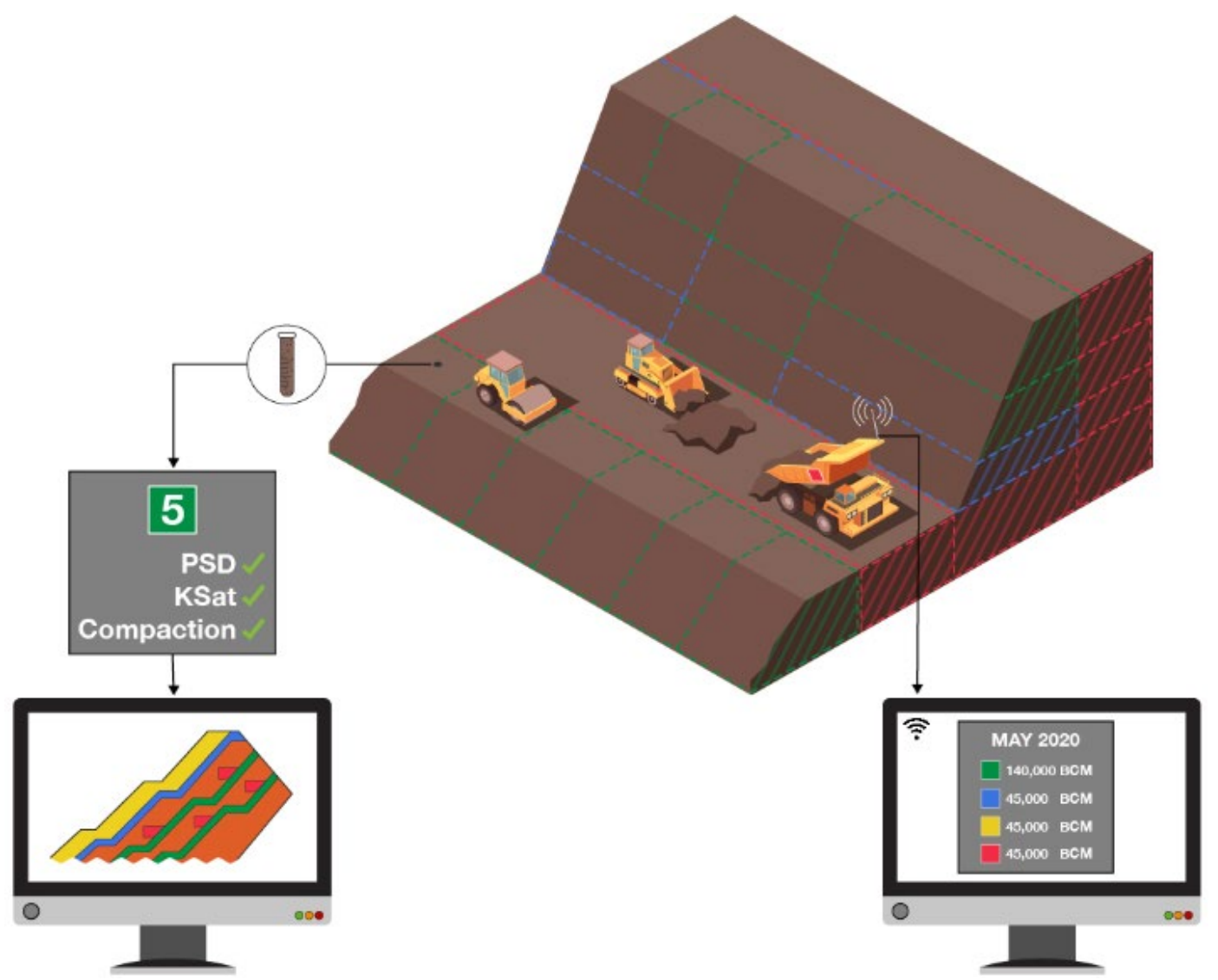

Figure 7 Conceptual figure showing short-term planning activities within integrated waste storage facility 
The short-term planning activities related to material placement as shown in Figure 7 include:

- Movement of waste into the IWSF area and tracking of all material movements using fleet management system (daily).

- Placement of waste into specific locations based on placement guidelines (daily).

- Compaction of materials according to geotechnical specifications (daily).

- Validation of as placed material properties through validation testing (monthly reporting).

- Production of as-built record based on data gathered from these activities (monthly reporting).

Forward planning of the placement of waste is carried out on a monthly basis to ensure that short-term plans for mining are matched to material requirements for placement at dumping destinations around the site. Figure 8 shows an example of a short-term placement plan for one month's material placement within the IWSF embankment. Volumes are broken down by individual waste class.

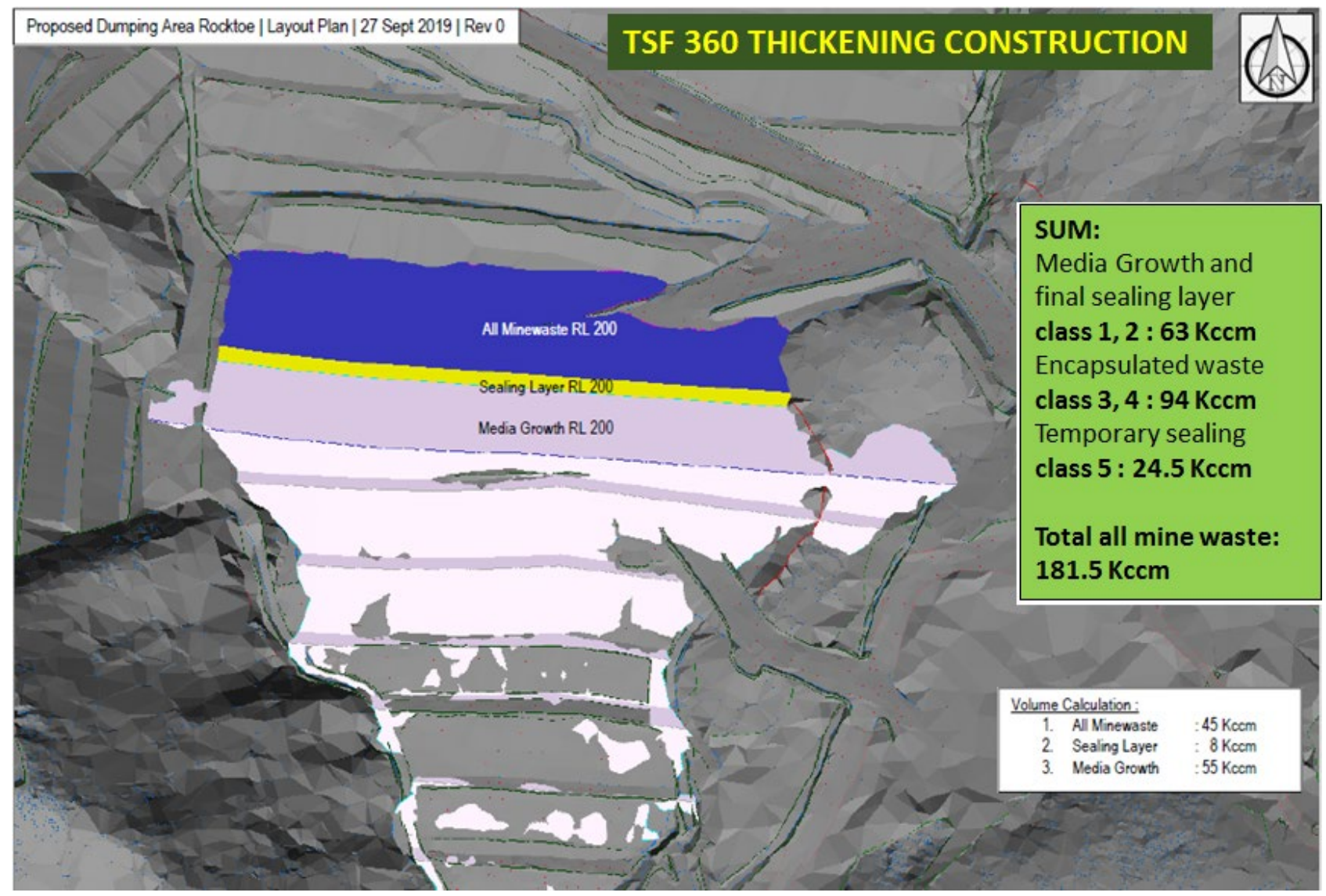

Figure 8 Conceptual figure showing short-term forward plan for material placement within integrated waste storage facility construction

\section{Application of ore grade control principals to acid and metalliferous drainage waste risk management}

The Martabe deposits have distinctly different AMD risks due to the varying geochemistry, which has been assessed from interrogation and testing of resource drilling data (Pearce et al. 2016, 2017). This has identified some counter-intuitive outcomes including the presence of higher risk soluble acidic sulphate salts from the lowest sulphide deposit and lower risk alumino sulphate minerals such as alunite in the high sulphur deposits. These findings have been further confirmed by additional close spaced data from intensive waste grade control reverse circulation (RC) drilling. 
Due to the varying nature of the deposits and need for immediate placement to final profile in the IWSF construction, a waste grade control philosophy has been implemented resulting in waste being defined similarly to ore control through detailed sampling, modelling and classification for optimum construction placement and AMD risk management. Full reconciliation between the waste grade control and reserve waste model is also carried out monthly to provide constant feedback on variance in predicted versus actual waste volumes and quality, and to validate the reserve AMD model. Reconciliation refines the rolling three month waste schedules for placement within the embankment to ensure specific elements of the closure strategy can be realised, particularly QA of the outer growth medium zone and internal sealing layers.

Figure 9 shows a comparative graphic reconciliation between the grade control block model based on ore control RC close spaced drilling on the left and the long-term planning reserve model block model based on exploration diamond drilling and resource development RC drilling on the right. The monthly variance is determined from these comparisons. Note the variations in classification between the reserve model and more detailed grade control model, which is tracked for further long-term planning improvement.

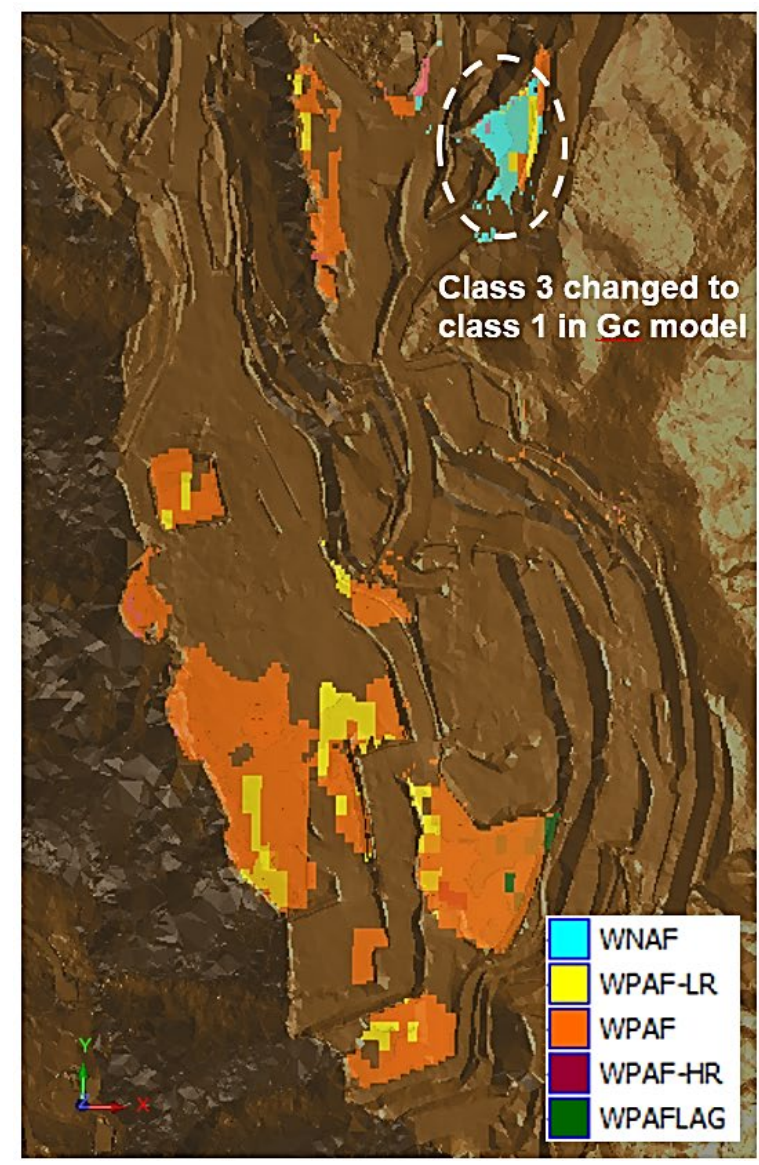

(a)

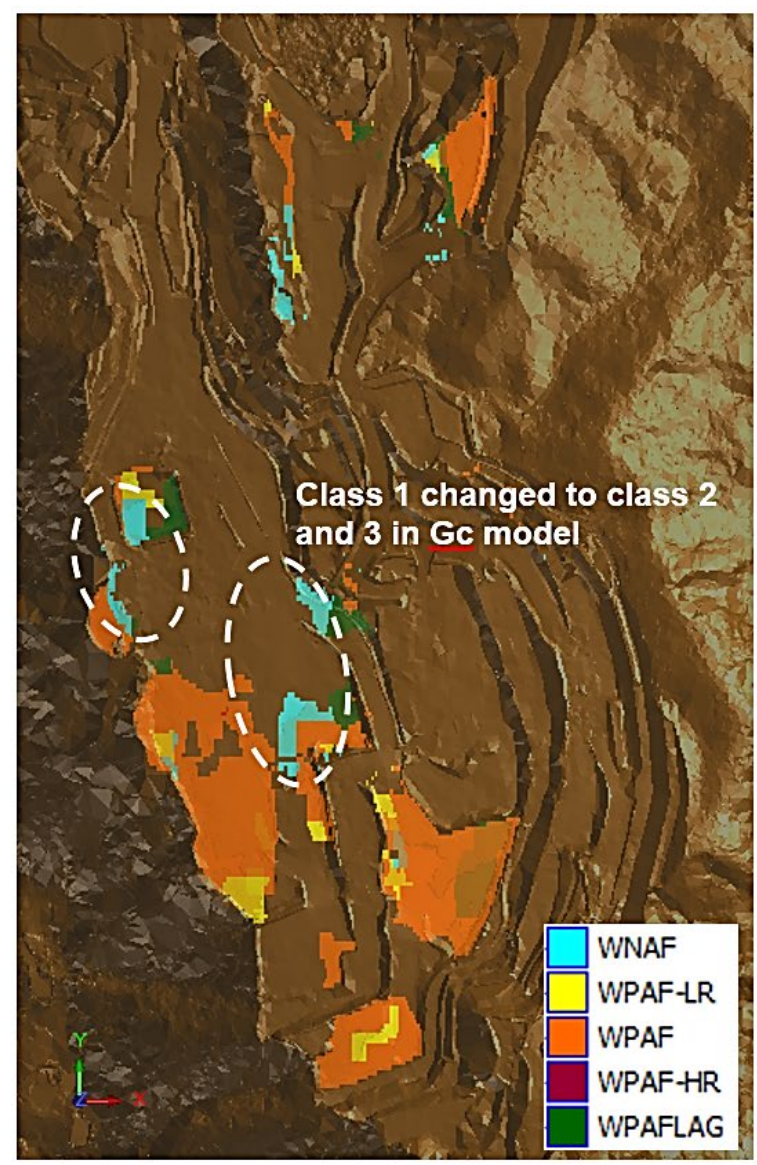

(b)

Figure 9 (a) Conceptual figure showing reconciliation between grade control; (b) Reserve block models

The AMD classification tables for both long-term reserve modelling and grade control validation modelling are pit specific and require a variety of material testing methods for specific application to the geochemistry risks of each deposit. Table 2 shows an example of the modelling parameter for one pit (Ramba Joring). 
Table 2 Reserve model acid and metalliferous drainage classifications for Ramba Joring, including alunite influence

\begin{tabular}{|c|c|c|c|c|c|c|}
\hline $\begin{array}{l}\text { Waste } \\
\text { class }\end{array}$ & Description & $\begin{array}{l}\text { Outside Alunite } \\
\text { domain: NAPP } \\
\mathrm{kg} \mathrm{H}_{2} \mathrm{SO}_{4} / \mathrm{t}\end{array}$ & $\begin{array}{l}\text { Inside Alunite } \\
\text { domain: NAPP } \\
\mathrm{kg} \mathrm{H}_{2} \mathrm{SO}_{4} / \mathrm{t}\end{array}$ & $\begin{array}{l}\text { Outside Alunite } \\
\text { domain: ANC kg } \\
\mathrm{H}_{2} \mathrm{SO}_{4} / \mathrm{t}\end{array}$ & $\begin{array}{l}\text { Other } \\
\text { parameters }\end{array}$ & $\begin{array}{l}\text { Sealing } \\
\text { layer }\end{array}$ \\
\hline 1 & NAF & $<0$ & & & Lith $\neq$ BFZ & Alt $=$ argillic \\
\hline 2 & $\begin{array}{l}\text { PAF - low } \\
\text { risk }\end{array}$ & $0-15$ & $\begin{array}{l}\text { (where SS = } \\
\text { SxS -3\%) }\end{array}$ & & Lith $\neq$ BFZ & Alt $=$ argillic \\
\hline 3 & PAF & $>15<90$ & & & Lith $\neq$ BFZ & No \\
\hline 4 & $\begin{array}{l}\text { PAF - high } \\
\text { risk }\end{array}$ & $>90$ & & & Lith $=$ BFZ & No \\
\hline 5 & PAF - LAG & $>15<90$ & & $>10$ & Lith $\neq$ BFZ & Alt $=$ argillic \\
\hline
\end{tabular}

Net acid producing potential (NAPP), acid neutralising capacity (ANC), non acid forming (NAF), potentially acid forming (PAF), lagging (LAG), lithology (Lith), breccia fault zone (BFZ), lagging PAF (PAF-LAG), SxS - sulphide sulphur.

The common criteria applied to all pit reserve models is the net acid producing potential (NAPP) since this can be readily calculated from attributes within the resource model and collected in the grade control sampling. However, the use of NAPP is assessed pit by pit as in some cases additional parameters (confirmed to be available in the reserve model) are required as part of grade control validation. For example, it was found that the presence of alunite in Ramba Joring pit needs to be factored as part of the NAPP calculation as the standard sulphide sulphur (SxS) analysis method using was used as part of the drillhole assay process was found to be significantly influenced by the presence of alunite. The standard sulphide sulphur analysis uses a sulphate leach to dissolve any sulphate mineralisation permitting the residual sample to be analysed for sulphur, hereafter referred to as the sulphide carbonate insoluble sulphur (SCIS) method. The inaccuracy of the SCIS method identified through use of the net acid generation test (NAG), chromium reducible sulphur (CRS) test and mineralogical analysis using an X-Ray Diffractometer (XRD) that indicates that sulphur present as sulphate in alunite is reported as SxS by the SCIS method in the NAPP model. It is important to note that in this case mineralogy is able to be modelled because Analytical Spectral Device (ASD) data using nearinfrared spectroscopy has been included in the reserve model dataset, as such zones where waste mineralogy is dominated by alunite can be included as a discrete domain in the reserve model (after wireframe modelling of ASD data has been integrated). This finding therefore also demonstrates the value that ASD data can provide when used as part of waste characterisation and modelling within reserve model as without it modelling the alunite zones would be significantly more difficult. The identification of this mineralogical control factor is key because it presents an opportunity to reclassify typically PAF material (class 3 ) to low PAF (class 2) within the reserve model which has considerable influence on the LOM waste materials delivery plan as the class 2 material has been identified as suitable material for use as part of the outer growth medium profile of the IWSF construction which allows this zone to be significantly thicker than would otherwise be possible.

A practical independent validation check of the material classification adopted in the reserve model based on AMD risk has been provided by implementing site based validation testing that is incorporated as part of the grade control validation works. These include:

- Kinetic testing assessment using intermediate bulk container (IBC) leach tanks to assess samples of Ramba Joring material over a range of SxS grades and alunite contents was initiated to provide data on drainage chemistry and AMD risk. The results to date indicate that material that was indicated from SCIS data to have sulphide grades of between $0.5-2 \%$, and where alunite content from ASD data was $>10 \%$ and where $\mathrm{NAGpH}$ values of $>4$ were recorded, has a very low release rate of acidity or mobile metals. 
- $\mathrm{QA} / \mathrm{QC}$ analysis using the CRS method, XRD and NAGpH testing was completed to provide comparative analysis data to compare SxS data obtained from the SCIS method. The results indicate that for grades of $<3 \% \mathrm{SxS}$, where alunite is present $>10 \%$, then CRS results are $<0.15 \%$, NAGpH $>3.6$ and $\mathrm{NAG}$ acidity $<5 \mathrm{~kg} / \mathrm{t} \mathrm{H} \mathrm{SO}_{4}$. Taken together the results indicate that the alunite rich material has very low to negligible sulphide content and has a low potential to release significant acidity.

- Oxitop testing (OxiTop ${ }^{\circledR}$ ) indicates that samples of material which reported SxS results of between 0.5 and $2 \%$, and where alunite content from ASD was $>10 \%$, have low oxygen consumption rates $<0.5 \mathrm{~kg} / \mathrm{t}$ p.a. $\mathrm{O}_{2}$. This data indicates that reactive sulphides are not present at appreciable levels.

- The Oxtitop observations in Figure 10 clearly show the differing oxidation rates based on oxygen consumption and supported by the column leach acid production tests. Tests 1-4 are from the highly reactive Barani pit material which contains sulphide dominant mineralogy indicating greater than 0.20 $\mathrm{kg} / \mathrm{t}$ over one month and test results 5-9 are from testing of samples with alunite dominant mineralogy from Ramba Joring which all have rates of less than $0.04 \mathrm{~kg} / \mathrm{t}$ over that same period.

\section{Oxygen consumption rate}

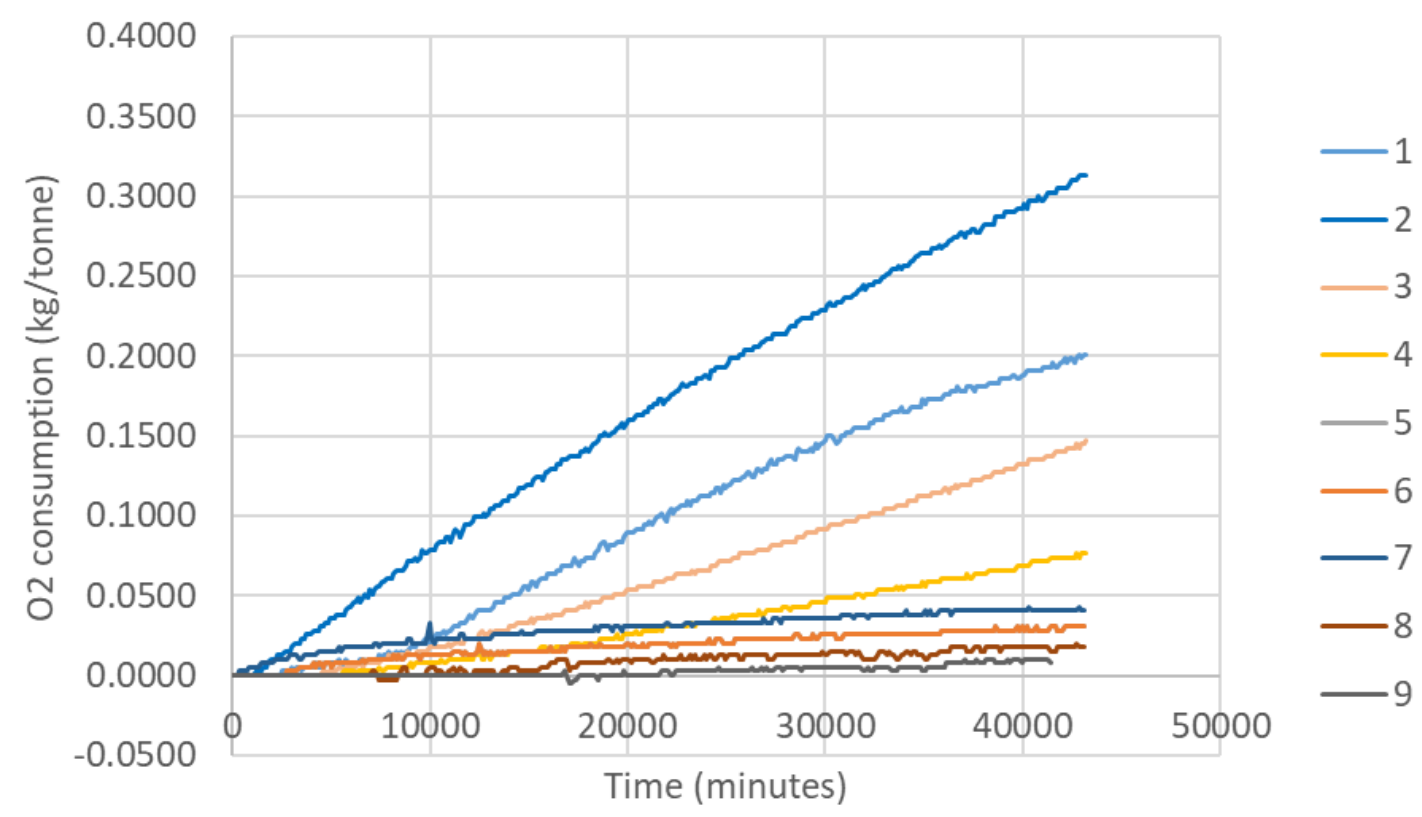

Figure 10 Relative Oxitop oxygen consumption results from Barani and Ramba Joring

Based on the validation work carried out for the reserve model parameters, practical grade control (GC) validation criteria have then been developed that can be demonstrated to both accurately determine AMD risk and are able to be practically implemented into GC drilling modelling. The practical implementation of AMD parameters into GC modelling is an important and often overlooked point as in many cases geochemical validation criteria are developed based on geochemical test outputs that are not able to be successfully modelled as part of integrated ore/waste GC modelling. For example, although NAGpH has been identified as a suitable test to identify lower risk alunite material (where sulphur is present as alunite not sulphides) a $\mathrm{pH}$ value is not strictly suitable for estimation modelling purposes as model estimation uses variography to average values between samples but $\mathrm{pH}$ being a log value cannot be averaged. Table 3 shows the grade control criteria developed based on assessment of appropriate values for model estimation purposes, NAG acidity and ANC values have been selected for GC model estimation purposes as these inputs are compatible with the integrated ore/waste GC model. 
Table 3 Grade control model acid and metalliferous drainage classifications for Ramba Joring

\begin{tabular}{|c|c|c|c|c|c|}
\hline $\begin{array}{l}\text { Waste } \\
\text { class }\end{array}$ & Description & $\begin{array}{l}\text { ANC lab } \\
\text { titration }\end{array}$ & NAG acidity & NAGph & $\begin{array}{c}\text { Other } \\
\text { parameters }\end{array}$ \\
\hline 1 & NAF & $\geq 0$ & $<0$ & NA & Lith $\neq$ BFZ \\
\hline 2 & $\begin{array}{l}\text { PAF - low } \\
\text { risk }\end{array}$ & $\geq 0$ & $<5$ & NA & Lith $\neq$ BFZ \\
\hline 3 & PAF & $<10$ & $>5<90$ & NA & Lith $\neq$ BFZ \\
\hline 4 & $\begin{array}{l}\text { PAF - high } \\
\text { risk }\end{array}$ & $<-5$ & $>90$ & NA & Lith $\neq$ BFZ \\
\hline 5 & PAF - LAG & $>10$ & $>5$ & NA & Lith $\neq$ BFZ \\
\hline
\end{tabular}

\section{$4 \quad$ Multi-mine optimisation and integrated waste quality scheduling for life-of-mine development planning}

Traditional Whittle optimisation is used for separate economic evaluations of the various deposits, however synergies have been identified with multi-pit development, which can only be evaluated using multiple integrated optimisation. This application has been expanded from the economic evaluation of ore, to the evaluation of waste with respect to potentially AMD risk. In order to quickly evaluate the likely material delivery of both ore and waste from multi-pit development a series of LOM strategies have been evaluated using the Whittle-based Geovia SIMO optimisation with various deposit specific parameters, constraints, restrictions and synergies applied.

The resulting methodology has assessed the sensitivity of several variables and impacts of any compromise between NPV and material delivery for progressive rehabilitation and the sustainable closure objectives. The outcome was an improved NPV, while satisfying the IWSF construction schedule and progressive AMD management requirements aligned to the mine closure objectives.

As an adjunct to the base case of the standard carbon in leach (CIL) process, a mine expansion sulphide process has now been developed and similarly assessed for all deposits simultaneously. This has resulted in an integrated plan that also optimises the crossover point from CIL to sulphide processing and provides a supporting schedule to guide a pre-feasibility study for the upgrade.

In the case of Martabe, the six deposits have considerably different sensitivities and AMD risks, mainly driven by the ore characteristics, including orientation, grade distribution, hardness, strip ratios, SxS, base metal and alunite distribution and argillic content. Additional constraints have been added to ensure delivery of sufficient argillic and lower risk alunite waste material for effective AMD control using the sealing layer stage construction concept (Figure 5), and applying new technology (Paterson 2017) which permits the recovery and re-use of about $50 \%$ of the cyanide and recovery of cyanide soluble copper (CuCN) which was previously a deleterious element.

The multi-mine SIMO output of pit staging honours the deposit value portions and considers the synergies of differing attributes by deposit by stage development and blending, making best use of these for the optimum NPV and AMD mitigation solution. This methodology has now been developed for routine annual updates of the LOM plan and three year budget using the commercially available SIMO software (Dassault Systemes ca. 2017), which is an earlier version (Prober B) of the enterprise optimisation (EO) process (Prober E).

The resulting schedule provides sufficient material in a timely manner for effective progressive rehabilitation of the outer profile of the IWSF.

Figure 11 shows an example of IWSF build schedule developed from LOM waste production schedule where requirements for material types are assessed and validated across the entire build plan. 
TSF build schedule (TSF1)

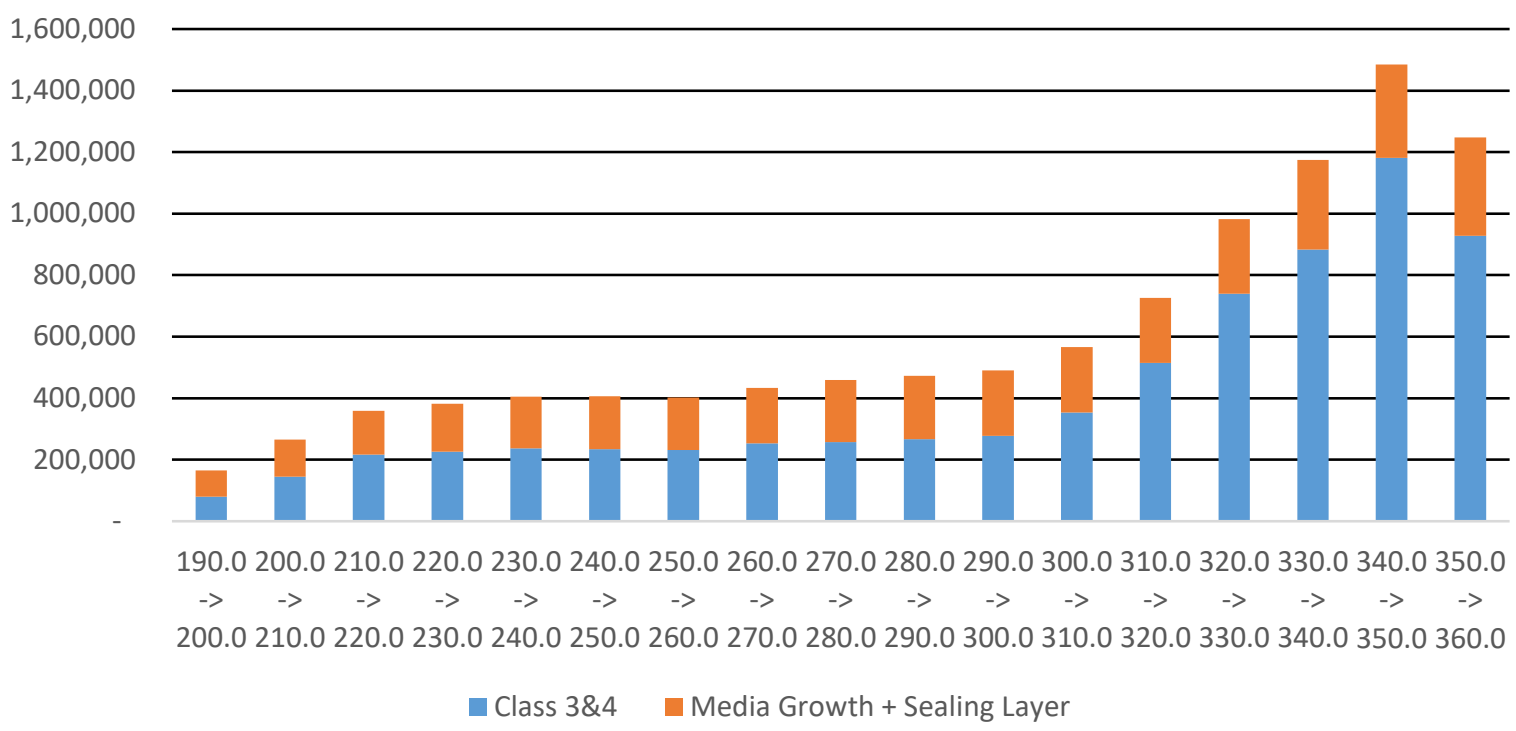

Figure 11 Example of life-of-mine build schedule developed for integrated waste storage facility construction based on material requirements against $R L$ of construction

\section{Conclusion}

The work carried out to date at the Martabe site has demonstrated that a holistic approach to the management of waste, including uneconomic mine waste and tailings can practically be incorporated into strategic planning for alignment with longer-term objectives and dealt with on a daily basis using a similar approach to ore control. The key benefit of the process is to ensure that waste management is given the appropriate priority and stewardship to achieve long-term closure objectives and that it permits new risks and opportunities to be identified early and resolved in a timely manner with reasonably rapid consideration of the various implications and opportunities.

The currently adopted waste disposal and facility construction, with intermediate and final sealing layers, has progressed successfully to date as a direct result of the integration of waste scheduling and planning with short and long-term mine planning operations. Validation of the process is indicated by monitoring results (reported in previous publications, Pearce et al. 2016, 2017) indicating that performance of the AMD management concept is inline with predictions.

The success of the process requires that LOM planning processes are aligned and consider pit optimisation in terms of mining for waste as well as ore, which in itself requires a fundamental paradigm shift in how mine planning is currently approached.

\section{Acknowledgements}

The following personnel have also contributed to the development of the concepts and implementation of the progressive AMD management and planning processes: M Barteaux, Mike O'Kane, O'Kane Consultants Inc., Canada; Matthew Orr, Janjan Hertrijana, Henny Purnamasari, Rahmat Lubis, Aris Tambunan, Mika Purba, Agincourt Resources, Indonesia; Steven Pearce, Mine Environment Management Ltd, United Kingdom; and Jason Pan, Whittle Consulting, Australia.

\section{References}

Dassault Systemes ca. 2017, Advanced Simultaneous Optimization, version 4.7.1, computer software, Dassault Systemes, Waltham, https://www.3ds.com/products-services/geovia/products/whittle/whittle-simo/ 
Paterson, MR 2017, 'The recyn process - changing the negative perception of cyanide', Proceedings of the Gold-PM Conference, ALTA Metallurgical Services, Melbourne, https://greengoldengineering.com/wp-content/uploads/2017/06/ALTA-2017-GPMGreen-Gold-Engineering-PAPER.pdf

Pearce, S, Barteaux, M, Grohs, K, Hertrijana, Purnamasari, H, Orr, M \& Nugraha, C 2017, 'Progressive management of AMD risk during construction of an integrated waste storage landform - a case study at Martabe Gold Mine, Indonesia', in C Wolkersdorfer, L Sartz, M Sillanpää \& A Häkkinen (eds), Proceedings of the 13th International Mine Water Association Conference, Lappeenranta University of Technology, Lappeenranta.

Pearce, S, Orr, M, Grohs, K \& Pearce, J 2016, 'Progressive mine closure - Martabe as a case study', AB Fourie and M Tibbett (eds), Proceedings the 11th International Conference on Mine Closure, Australian Centre for Geomechanics, Perth, pp. 619-635. 